\title{
Interventional Study Protocol Version Blinding Schema Code
}

National Cancer Institute

\section{Source}

National Cancer Institute. Interventional Study Protocol Version Blinding Schema Code. NCl Thesaurus. Code C93853.

A coded value specifying the type of masking used on a study protocol to ensure that the results are not biased by the subjects or investigators. 